\title{
Analysis of IT/Business Alignment Situations as a Precondition for the Design and Engineering of Situated IT/Business Alignment Solutions
}

\author{
Jan Saat, Robert Winter \\ Institute of Information Management \\ University of St. Gallen \\ St. Gallen, Switzerland \\ \{jan.saat, robert.winter\}@unisg.ch
}

\author{
Ulrik Franke, Robert Lagerström, Mathias Ekstedt \\ Industrial Information and Control Systems \\ The Royal Institute of Technology (KTH) \\ Stockholm, Sweden \\ \{ulrikf, robertl, mek101\}@ics.kth.se
}

\begin{abstract}
IT/business alignment has constantly been among the top priorities for IT executives. From a prescriptive, design research perspective, our analysis of related work shows that neither is IT/business alignment sufficiently specified to allow systematic artifact construction, nor are existing approaches situational to reflect the diversity of IT/business alignment problems in the real world. We use goal decomposition to characterize IT/business alignment by qualities from (i) the IT systems, (ii) the business, and (iii) the IT governance perspective. A survey-based exploratory study among 174 professionals from various European countries is conducted that helps to identify four distinct IT/business alignment situations. This knowledge can now be used to construct methods and models that do not only operationalize alignment, but also can be adapted to the different situational needs.
\end{abstract}

\section{Introduction}

IT/business alignment has constantly been among the top priorities for IT executives [1-4]. Research on IT/business alignment can take a descriptive or a prescriptive perspective: On the one hand, the IT/business alignment phenomenon needs to be better understood. On the other hand, artifacts need to be constructed on the foundation of that understanding which enhance or extend IT/business alignment. We concentrate on the latter research perspective. Our analysis of related work, i.e. existing methods and models, in section 2 shows that different problem contexts (e.g. industry, company size) or different goals (e.g. improving transparency, reducing inconsistencies, improving flexibility) are usually not considered. As diverse problem situations require different solution designs, prescriptive research should provide situated or at least adaptable solutions instead of 'one-size-fits-all' artifacts and might thereby en- hance or extend their utility. As a precondition for constructing such solutions, however, precise specifications of relevant IT/business alignment situations are needed. Our literature search has not discovered such knowledge.

The contribution of this paper is therefore to identify as-is situations for IT/business alignment. As IT/business alignment is a very widely used and 'fuzzy' term, means of goal decomposition are used to characterize IT/business alignment by qualities from (i) the IT systems, (ii) the business, and (iii) the IT governance perspective. Furthermore, a survey-based exploratory study among 174 enterprise architecture professionals from various European countries is conducted. Using statistical methods such as factor analysis and hierarchical clustering, four problem situations for IT/business alignment are identified and characterized in terms of the most important qualities in each situation. Additionally courses of action (priorities for to-be states) are identified.

Based on the better understanding of IT/business alignment situations, situational artifacts (like e.g. methods and models) can be constructed and can be systematically adapted to create situational utilities.

The remainder of this paper is structured as follows: Section 2 presents and discusses related work in the fields of enterprise architecture and IT/business alignment. In section 3, the often 'fuzzy' understanding of IT/business alignment is operationalized by considering qualities of IT systems, business, and IT governance. The herein presented research framework is then subjected to an empirical analysis of IT/business alignment situations, presented in section 4. After describing the setup and the analysis method, four IT/business alignment situations are identified. The limitations of the results are reflected in section 5 , and the paper is summarized in section 6 . 


\section{Foundations and related work}

\subsection{IT/business alignment}

The framework proposed by Henderson and Venkatraman [5] is widely applied and is generally considered to be a key reference alignment model. It contains four components needed for alignment assessment, viz. (1) business strategy, (2) IT strategy, (3) organizational infrastructure and processes, and (4) IT infrastructure and processes. The interactions of these four components along two dimensions, strategic integration and functional integration, form the state space of the model. Neither do the authors propose solution artifacts, nor do they consider situational differences of IT/business alignment problems.

Luftman [6] develops a strategic alignment measurement tool based on detailed maturity models covering six distinct areas: (1) communications, (2) competence/value, (3) governance, (4) partnership, (5) technology scope, and (6) skills maturity. This work was later extended in [7] into the Strategic Alignment Maturity Assessment (SAMA). While an assessment tool can be considered as an artifact that supports problem solution, no situational characteristics are covered by Luftman's approach.

Based on an empirical study Baumöl [8] argues that IT/business alignment can only be achieved when using a systematic change method. She proposes such a method, called Change Method Engineering, which is based on empirical findings of critical IT/business alignment success factors. The approach is based on a taxonomy of transformation problems and thus can be considered as situational. The situations are however defined regarding general transformation and not regarding IT/business alignment.

\subsection{Enterprise architecture}

Enterprise architecture (EA) has been proposed as an approach for managing business and IT artifacts on a strategic level. EA targets a holistic and unified scope of an organization [9, 10]. This overarching perspective is also present in the ANSI/IEEE Standard 1471-2000, defining architecture as "the fundamental organization of a system, embodied in its components, their relationships to each other and the environment, and the principles governing its design and evolution" [11]. As a consequence of this wide scope, EA is typically not limited to IT, but also encompasses the relation and support of IT to the business. Thus, in many respects EA can be seen as a tool for achieving alignment between business and IT.
If the joint scope of IT and business is one defining part of EA, its model-based methodology is another. As the name hints, architectural descriptions are central in EA. These descriptions include entities covering a broad range of phenomena, such as strategic aspects, organizational structure, business processes, software and data, as well as IT infrastructure [12-14]. A large number of EA frameworks have been proposed, each detailing the kind of entities that should be part of the modeling effort. Some examples are [13, 15-18].

Essentially, EA models serve the purpose of helping various stakeholders of the organization to document and understand the enterprise's complexity, analyze the properties of current and potential future scenarios, plan and design future scenarios and the roadmap to get there, as well as communicating the current and future state of affairs to other stakeholders in the organization. Furthermore, by focusing on particular needs of decision-makers - modeling not for modeling's sake, but for particular purposes - EA can be used as a powerful decision-support tool [19].

\subsection{EA enabled IT/business alignment}

Since EA in many respects can be seen as tool for achieving alignment between business and IT, related work on EA enabled IT/business alignment is presented in this subsection.

While none of the approaches described so far explicitly include the notion of EA in IT/business alignment, several other publications argue that EA indeed can be a valuable instrument to manage IT/Business Alignment. Aier and Winter [20] propose what they call virtual decoupling to achieve IT/Business Alignment, i.e. an architecture-centric approach that separates the external view on architecture from its particular implementation. In so doing, the level of complexity is significantly reduced, thus enabling a more rational and less myopic approach to managing the IT/business alignment.

Plazaola et al. [21] explicitly attempt to represent strategic IT/business alignment in EA terms by proposing a meta model with the relevant entities and relations. They explain the criteria and the process for connecting Luftman's strategic alignment measures [6] with Zachman's Enterprise Architectural Framework [22]. However, the proposed meta model does not include any guidelines for how to apply it in particular enterprises. In the present contribution, we try to transcend this "one-size-fits-all” philosophy based on an empirical study. 


\section{Research framework to decomposing IT/business alignment}

As described above, IT/business alignment is a subject that has been widely covered in the literature, including work on EA enabled IT/business alignment. However, in order to get deeper insights into the alignment phenomenon, it is necessary to stipulate some definitions and operationalizations. In order to accomplish this, it is assumed that IT/business alignment can be understood as a design goal that companies strive for.

In order to be able to reach this design goal, it is necessary to delineate the design parameters which are available to enterprise architects and decision makers. In order to enumerate these parameters, a number of qualities contributing to IT/business alignment are derived from existing research, standards and best practices. These qualities encompass (i) IT system qualities, (ii) business qualities, and (iii) IT governance qualities. Figure 1 illustrates the approach conceptually. In particular, the jigsaw puzzle metaphor is intended to convey that no single set of qualities has primacy over any other. The role of the enterprise architects and decision makers is to make all the pieces fit together into a unified whole. IT/business alignment arises in the interaction of all the qualities and can be achieved only by adjusting all of them so that they fit each other.

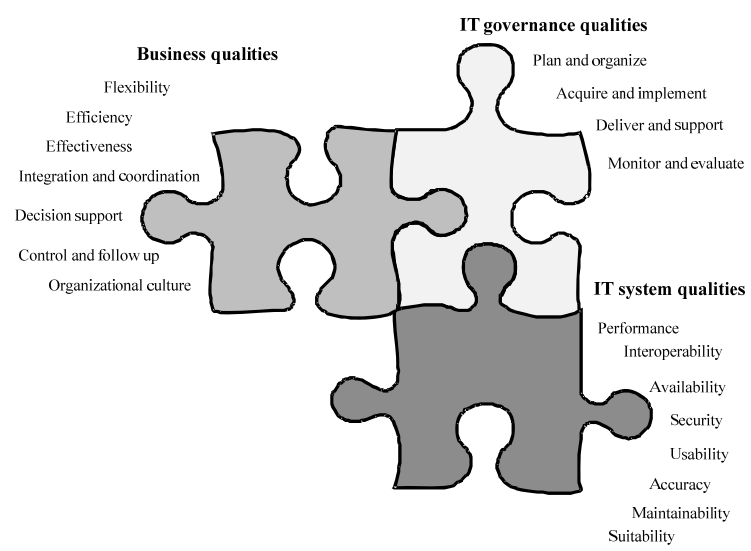

Figure 1. A conceptual view of an IT/business alignment operationalization.

In subsequent subsections, each of the three areas - (i) IT system qualities, (ii) business qualities, and (iii) IT governance qualities - is detailed.

\subsection{IT system qualities}

The IT system qualities employed are based on the ISO 9126 standard [23-26]. These qualities have also been used in the book Enterprise Architecture Models and analyses for information systems decision making by [19]:

Performance, or efficiency, as the ISO/IEC 9126 labels it, is a quality that characterizes how much work a system can perform and how fast. Performance is defined as the degree to which an IT system can meet its objective in terms of scalability and responsiveness [27].

Interoperability is described as the ability of two or more systems or components to exchange information and to use that information [28]. Interoperability is defined in terms of two kinds of data exchangeability, one related to data formats and the other related to a user's attempts to exchange data [26].

The availability of a system indicates how often a system is ready to deliver its services to its users. Post factum, availability is defined as the ratio between the system's time in service (uptime) and the total time (uptime plus downtime), i.e. a system's mean time to failure (MTTF) plus its mean time to repair (MTTR) [19].

The most common definition of IT system security is how well the system is capable of preserving the confidentiality, integrity and availability of its internal information [29, 30].

The usability of a system reflects how easy it is for a user to interact with and perform his or her tasks in the system. [24] defines usability as the understandability, learnability, operability and attractiveness of an IT system.

The accuracy of an IT system is measured by the degree to which it produces resulting data that is accurate and precise. This is determined by comparing the output value with the expected or "real" value. Precision, on the other hand, refers to how repeatable the output is, i.e. if the same input data gives the same output data [19].

The ease with which an IT system can be modified or adapted to a changed environment is referred to as maintainability, sometimes also identified as modifiability [28, 31]. Inspired by [31] maintainability is defined by the five sub-qualities, namely flexibility, reusability, extensibility, portability, and integrability. These describe the different kinds of changes a system can be exposed to during its lifetime.

The suitability of an IT system is the degree to which the functionality of the system supports the system's intended work tasks. That is, a suitable system offers the functions specified in the requirements specification, and meets user expectations with regard to functionality. The definition of suitability used here is borrowed from [26]. This definition stipulates that a system's suitability is contingent upon the systems functional adequacy, functional implementation com- 
pleteness, functional implementation coverage and functional specification stability.

\subsection{Business qualities}

The business qualities are based on a taxonomy originally presented by Gammelgård et al. [32] which is based on a literature consolidation of over 500 papers and 20 books. The particular subset of this taxonomy employed in the present survey is that used by Gustafsson et al. [33]:

Flexibility is defined as the degree to which the business processes and organizational units in a company have the ability to adapt to changes in market conditions/requirements, e.g. changed demand, political and economical factors.

Efficiency concerns the degree to which the business processes in a company exhibit short manufacturing times/lead times/cycle times/work times, much automation of work etc.

Effectiveness i.e. the degree to which the business processes in a company produce what the market demands and spend little time on paperwork and administration.

Integration and coordination focuses on the degree to which the organizational units in a company have the ability to integrate and coordinate different parts of the organization, i.e. coordination of the production and the distribution department, of the sales and production planning departments etc.

Decision support deals with the degree to which an organizational unit has proper decision support, i.e. makes well-informed decisions, decisions are taken close to operations, decisions have high reliability and low uncertainty, decisions made are accepted by the organization etc.

Control and follow up is defined as the degree to which an organization have the ability to control and follow up work i.e. decisions are evaluated in retrospect, lessons learned are documented and re-used, new projects take previous experiences into account etc.

Organizational culture means to what degree the organizational culture in a company is appreciated by the people working at the company, i.e. there is a high job satisfaction and motivation, no negative stress, low numbers of sick leave etc.

\subsection{IT governance qualities}

The IT governance qualities are based on the four main processes of the well-known COBIT standard [34]:
Plan and organize covers strategy and tactics, and concerns the identification of the way IT can best contribute to the achievement of the business objectives.

Acquire and implement is about realizing the ITstrategy, identifying, developing, or acquiring ITsolutions, as well as implementing and integrating these into the business processes.

Deliver and support is concerned with the actual delivery of required services, which includes service delivery, management of security and continuity, service support for users, and management of data and operational facilities.

Monitor and evaluate addresses performance management, monitoring of internal control, regulatory compliance and governance in order to keep or improve quality and compliance with control requirements.

\section{Empirical analysis of IT/business align- ment situations}

The main contribution of this paper is to identify a set of relevant as-is situations of IT/business alignment. Embarking on this study, there is no preconception of the differentiation of approaches - whether particular lines of business, company sizes, IT concerns or what not would turn out to be suitable for particular meta model fragments. This justifies an exploratory research methodology.

\subsection{Data collection, characterization of the data set and description of the survey}

An online survey was used for data collection. Prior to distribution, the survey was pretested with EA experts and valuable comments were received and addressed. Invitations were emailed to EA professionals in Sweden, Switzerland, Austria and Germany. The email addresses were condensed from the attendance lists of several EA practitioner conferences. Additionally a web link to the survey was posted on several EA community websites. Out of 1105 invitations sent, 92 emails bounced, 339 persons started and 174 persons completed the survey. The online survey was active for ten days (Sept. 11-21, 2009). The survey included a final question regarding the respondent's confidence with his or her answers. Twelve persons stated weak confidence so their answers were not further considered. A total of 162 completely filled in surveys are subjected to the following analysis. Figure 2 describes the dataset in detail.

The survey is comprised of four parts: Part one of the survey contains questions regarding the back- 


\begin{tabular}{|l|r|r|}
\hline Industry & Count & Percent \\
\hline Financial Industry & 49 & 30.25 \\
\hline Utility & 23 & 14.20 \\
\hline Manufacturing & 17 & 10.49 \\
\hline Other & 13 & 8.02 \\
\hline Transportation & 12 & 7.41 \\
\hline Telecommunication & 10 & 6.17 \\
\hline Software industry & 8 & 4.94 \\
\hline Public sector & 7 & 4.32 \\
\hline Defense/Military & 7 & 4.32 \\
\hline IT/Management-Consulting & 4 & 2.47 \\
\hline Healthcare/Pharmaceutical & 3 & 1.85 \\
\hline Engineering/Architecture & 3 & 1.85 \\
\hline Academia/Research & 2 & 1.23 \\
\hline Tourism & 2 & 1.23 \\
\hline Retail & 2 & 1.23 \\
\hline
\end{tabular}

\begin{tabular}{|l|r|r|}
\hline Size of Comany & Count & Percent \\
\hline$<100$ & 15 & 9.26 \\
\hline $100-1.000$ & 32 & 19.75 \\
\hline $1.001-5.000$ & 33 & 20.37 \\
\hline $5.001-10.000$ & 15 & 9.26 \\
\hline $10.001-25.000$ & 28 & 17.28 \\
\hline$>25.000$ & 39 & 24.07 \\
\hline
\end{tabular}

\begin{tabular}{|l|r|r|}
\hline Country & Count & Percent \\
\hline Austria & 4 & 2.47 \\
\hline Finland & 1 & 0.62 \\
\hline Germany & 28 & 17.28 \\
\hline Sweden & 73 & 45.06 \\
\hline Switzerland & 56 & 34.57 \\
\hline
\end{tabular}

\begin{tabular}{|l|r|r|}
\hline Area of Activity & Count & Percent \\
\hline Business Management & 28 & 17.28 \\
\hline Business Unit & 22 & 13.58 \\
\hline IT Department & 52 & 32.10 \\
\hline IT Management & 60 & 37.04 \\
\hline
\end{tabular}

Figure 2. Data set description.

ground of the respondents such as industry, country, and company size as well as the respondent's role and involvement with EA. Respondents employed by a consulting company had the option to answer on behalf of a client company. This option was used by 43 respondents. The second part of the survey has two sections. The first section contains questions addressing EA use for IT/business alignment and the importance and perceived maturity of IT/business alignment at the respondent's company. Section two contains more detailed questions related to IT/business alignment and the positioning of the IT department within the respondent's company. The third part of the survey addresses the qualities regarding IT, business, and IT governance as presented in section 0 . For each quality one statement was posted and the respondents were asked to mark the actual (as-is) situation (degree of realization) and desired (to-be) situation (importance for future realization) on a five-point Likert scale (where 1 equals very low, 2 equals low, 3 equals medium, 4 equals high, and 5 equals very high). The final part of the survey contains a question regarding the respondents' confidence regarding the answers as well as the possibility to submit questions and feedback to the authors.

\subsection{Research design}

First, the data is examined by factor analysis in order to identify a limited number of factors with a large explanatory power. Second, these factors are used as input for a clustering procedure that groups the problem descriptions represented by the respondent's data into a small number of clusters with different characteristics.
Exploratory factor analysis (EFA) is differentiated by [35] from confirmatory factor analysis (CFA). In EFA there is no specific preconceptions regarding the number of underlying factors, as opposed to the CFA case where there is "a firm a priori sense, based on past evidence and theory, of the number of factors that exist in the data, of which indicators are related to which factors, and so forth" [36]. The present study fits the EFA model and the three steps outlined above are not dependent on any particular number of factors being found. As it is put in [35], factor analysis is used "to summarize relationships in the form of a more parsimonious set of factor scores that can then be used in subsequent analyses" [35].

As [37] puts it, the idea of clustering is to investigate "a set of objects in order to establish whether or not they fall [...] into groups [...] of objects with the property that objects in the same group are similar to one another and different from objects in other groups.” Naturally, there are a large number of different clustering methods. In the present study, we have opted to use a hierarchical agglomerative method, identified by [38] as the type of algorithm having the largest significance in practice. Agglomerative algorithms start with $n$ singleton clusters, where after the number of clusters is reduced in each iteration until a suitable solution is found.

\subsection{Analysis and interpretation}

The qualities for IT/business alignment are used to conduct a factor analysis for the data set. This allows for the identification of common characteristics among the qualities using EFA. The sampling adequacy was evaluated using the Kaiser-Meyer-Olkin (KMO) 
measure. The KMO regards the diagonal axis within an anti image covariance matrix to evaluate the general suitability of the data set for factor analysis. In the case presented, the KMO is 0.918, which [39] regard to be "marvelous". The Kaiser-Guttmann criterion [40] and the elbow criterion [41] is used to obtain a desired number of factors. According to [40] the number of factors to be extracted should be equal to the number of factors with eigenvalues bigger than one. The elbow criterion can be satisfied using a scree test as proposed by [41]. For the data set at hand, the optimal number of factors is computed to be three. Figure 3 depicts the eigenvalues and the scree plot.

\begin{tabular}{|c|c|}
\hline Factor & Eigenvalue \\
\hline 1 & 6.81362481 \\
\hline 2 & 1.47233972 \\
\hline 3 & 1.34494215 \\
\hline 4 & 0.90251268 \\
\hline 5 & 0.82148246 \\
\hline 6 & 0.69465449 \\
\hline 7 & 0.62862558 \\
\hline 8 & 0.59902269 \\
\hline$\ldots$ & \\
\hline 17 & 0.29613778 \\
\hline
\end{tabular}

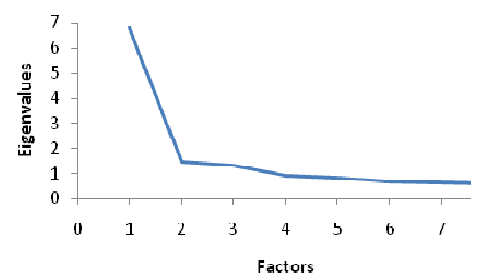

Figure 3. Factors and eigenvalues for EFA (left) and scree plot (right).

Principal component analysis is used to extract the factors. The goal of this approach is to identify few but independent factors that reduce the items according to common characteristics. Table 1 depicts the result of the factor analysis. In order to better understand and interpret the factors, the component matrix is rotated using the Varimax method and Kaiser normalization [42].

An item is assigned to a factor according to its factor load. The factor load is calculated using the correlation of a variable to the factor that was extracted from the data. In order for an item to be assigned to a factor, the respective factor load has to be the highest value for this item and also has to exceed 0.5 [38]. The items "Interoperability" and "Organizational Culture" (c.f. section 0) are removed from the analysis as the factor loads for these items were below 0.5 for all factors.

Factor 1 Business-driven planning consists of business and IT-governance concerns. Items such as decision support, control and follow-up, business flexibility, effectiveness, integration and coordination, acquire and implement as well as plan and organize load on this factor. Participants (and hence IT/business alignment problems) scoring high in this factor emphasize strong business orientation and a strong IT organization.
Table 1. Rotated component matrix.

\begin{tabular}{|l|l|c|c|c|}
\cline { 3 - 5 } \multicolumn{2}{l|}{} & \multicolumn{3}{c|}{ Factor } \\
\hline Cat. & Item & $\mathbf{1}$ & $\mathbf{2}$ & $\mathbf{3}$ \\
\hline BUS & $\begin{array}{l}\text { Decision Sup- } \\
\text { port }\end{array}$ & 0.753987 & 0.211965 & 0.188453 \\
\hline ITG & $\begin{array}{l}\text { Acquire and } \\
\text { Implement }\end{array}$ & 0.714991 & 0.186588 & 0.225826 \\
\hline ITG & $\begin{array}{l}\text { Plan and Organ- } \\
\text { ize }\end{array}$ & 0.677433 & 0.224612 & 0.277512 \\
\hline BUS & $\begin{array}{l}\text { Control and } \\
\text { Follow Up }\end{array}$ & 0.674663 & 0.096948 & 0.268977 \\
\hline BUS & $\begin{array}{l}\text { Integration and } \\
\text { Coordination }\end{array}$ & 0.637061 & 0.279205 & -0.019899 \\
\hline BUS & Flexibility & 0.636681 & 0.24160 & -0.235255 \\
\hline BUS & Effectiveness & 0.549010 & 0.483476 & 0.04557 \\
\hline ITS & Performance & 0.051344 & 0.776337 & 0.196293 \\
\hline ITS & Availability & 0.127147 & 0.69881 & 0.167507 \\
\hline ITS & Suitability & 0.318333 & 0.654633 & 0.142230 \\
\hline ITS & Usability & 0.275959 & 0.651576 & -0.073737 \\
\hline ITS & Accuracy & 0.184559 & 0.632516 & 0.338447 \\
\hline BUS & Efficiency & 0.512070 & 0.537886 & -0.002942 \\
\hline ITS & Maintainability & 0.417643 & 0.516266 & 0.120234 \\
\hline ITS & Security & -0.056182 & 0.159936 & 0.768478 \\
\hline ITG & $\begin{array}{l}\text { Deliver and } \\
\text { Support }\end{array}$ & 0.373640 & 0.321855 & 0.631850 \\
\hline ITG & $\begin{array}{l}\text { Monitor and } \\
\text { Evaluate }\end{array}$ & 0.531410 & 0.061938 & 0.620340 \\
\hline $\begin{array}{l}\text { BUS }=\text { Business quality, ITS }=\text { IT systems } \\
\text { nance quality }\end{array}$ & \multicolumn{3}{|c|}{} \\
\hline
\end{tabular}

Factor 2 System quality orientation subsumes high priority of performance, availability, usability, accuracy, maintainability and suitability of IT systems used. Therefore, companies (and hence IT/business alignment problems) scoring high in this factor focus on delivery of high-class and effective delivery of ITservices to users.

Factor 3 Compliance focus consists of the three items systems security, monitor and evaluate, and deliver and support. Common characteristics can be found in striving for a high degree of security and continuity of systems and business processes.

In order to identify as-is situations within the data set, hierarchical cluster analysis is applied to the factor values calculated above. The fusion algorithm used is the Ward algorithm using Eucledian squared distance. This course of analysis creates distinct clusters by minimizing the internal cluster variance. This is the most popular approach for hierarchical clustering [43]. The analysis results in four distinct situations as presented in Figure 4. The table presents the factor load for each cluster and the web diagram shows a graphical representation of these values. A characterization of the as-is situations is given below.

The identified clusters in this course of analysis represent as-is IT/business alignment situations within the analyzed sample. In order to gain deeper insight on the characteristics of each situation, further information on the perception of IT/business alignment and the usage of EA instruments is extracted from the data 


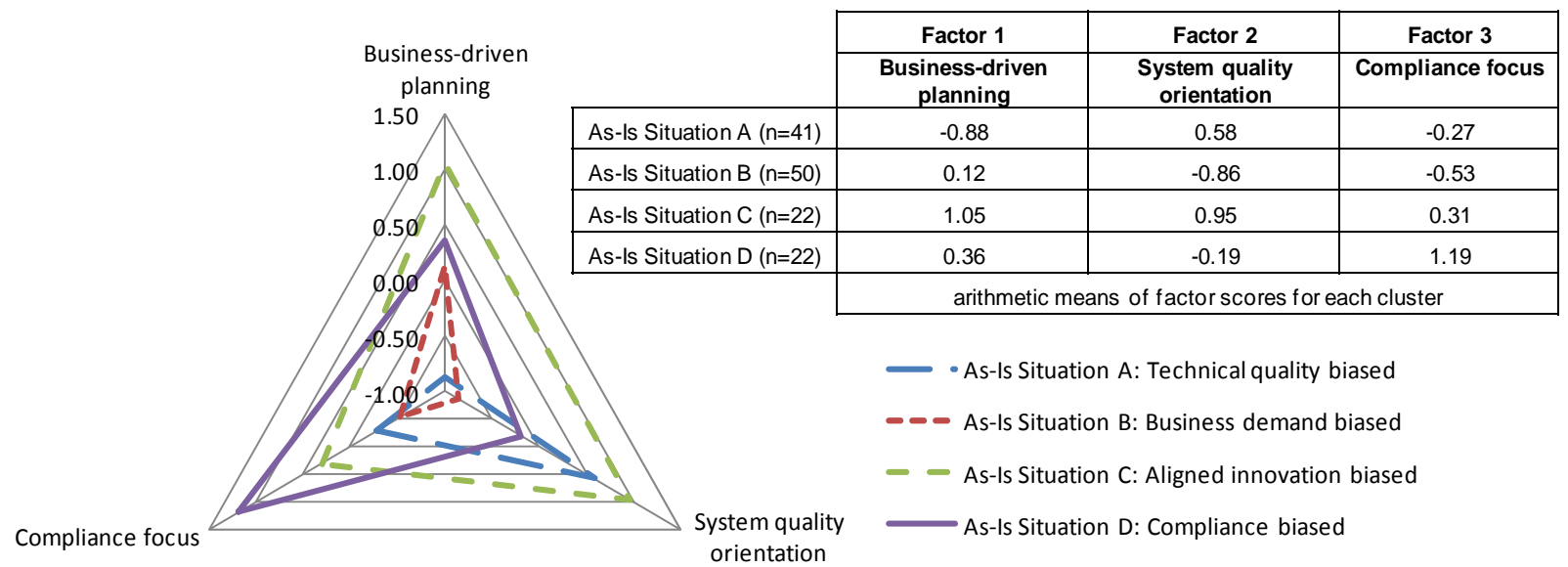

Figure 4. Identified IT/business alignment as-is situations.

set. Figure 5 graphs the arithmetic mean values of answers for each cluster.

\section{As-Is Situation A: technical quality biased}

The first situation scores highest on the factor system quality orientation. Business planning issues are not prioritized high. The analysis shows that IT/business alignment is perceived to be an important issue. However, the degree of IT/business alignment in the respective company is regarded to be rather low. EA is not seen as valuable instrument for IT/business alignment.

\section{As-Is Situation B: business demand biased}

Contrary to as-is situation A, business-driven planning is the most important issue for situation B. The experience of using EA instruments, such as models, processes, roles, and tools, is similar to these values for situation A, yet fairly low with 2.5 to 4 years.

\section{As-Is Situation C: aligned innovation biased}

Situation $C$ focuses on characteristics of all three factors and delivers equally high scores for business and the IT-driven dimensions, while also considerably incorporating compliance aspects. In this situation, EA is considered to be a valuable instrument for IT/business alignment. This is underlined by top scores in years of EA instruments usage. In this cluster, EA instruments have been used for 6 (tools) to 8.5 (models) years on average. This justifies the assumption that organizational implementation and EA maturity in this situation are quite high.

\section{As-Is Situation D: compliance biased}

This situation is compliance focused and business oriented. The situation is characterized by high perceived IT/business alignment and a fair history of EA usage (3.5 to almost 5 years). EA is regarded to be of valuable assistance in achieving IT/business alignment.

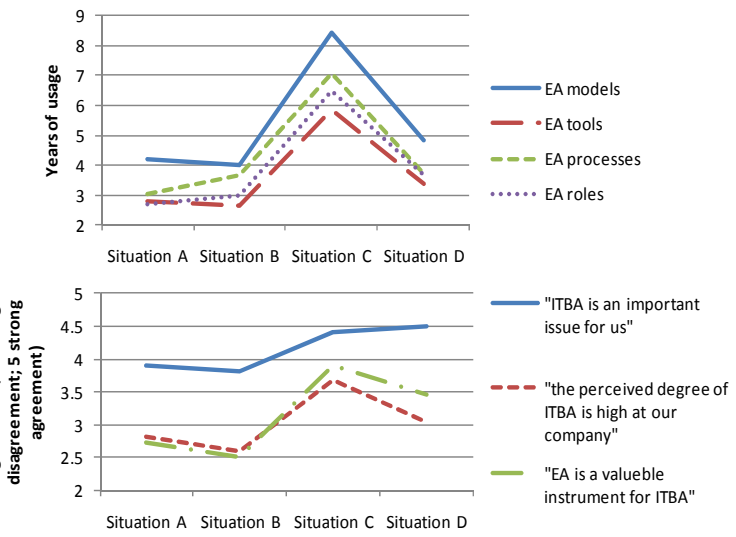

Figure 5. Characterization of as-is situations regarding usage of EA and perceptions on IT/business alignment.

\section{Limitations}

The data set consists of perceptions from individuals, where several completed surveys may originate from the same company. Therefore the results represent aggregated subjective responses that are suitable to derive trends within the presented situations. Due to the sample size a fair representation of trends within the results can be assumed. 
The present survey only generates a snapshot of the investigated companies and design problems. However, no correlation to the success-rate of the companies involved has been made. Further research needs to be conducted to identify whether particular success factors can be discerned, thus enabling even more powerful modeling recommendations.

\section{Conclusion}

Since most companies face different challenges regarding the goal of achieving a high degree of IT/business alignment, a prescriptive 'one-size-fitsall' solution seems not to be suited to solve these issues. As existing approaches do not distinguish different situations of IT/business alignment, this paper presents an approach to create situation-based solutions. IT/business alignment is addressed by considering tangible qualities for business, IT systems, and IT governance. An explorative study among 174 EA professionals is used to distinguish four different IT/business alignment situations. These situations each represent the current state according to different qualities and also the priorities for future development.

The presented approach combines a novel way to address the goal of IT/business alignment by considering tangible qualities. This may enhance the creation of goal oriented artifacts in design-oriented research. Furthermore, the paper contributes to the discussion on situational artifact construction.

In EA research, the identified as-is situations can serve as a foundation to build situational EA meta models. Thereby, each meta model has to focus on the qualities of the respective situation.

From a situational method engineering perspective, investigations on transformation paths should be conducted. Therefore the data set can be used to determine how the identified as-is situations can be transformed into respective to-be situations. This approach could also identify dominant transformation paths, e.g. if most companies in as-is situation A desire transformation to to-be situation $\mathrm{B}$. These insights from this analysis can then be used to create dedicated methods to support dominant transformation paths.

\section{References}

[1] J. N. Luftman, "Key Issues for IT Executives 2004," MISQ Executive, vol. 4, pp. 269-285, 2005.

[2] J. N. Luftman and R. Kempaiah, "Key Issues for IT Executives 2007," MISQ Executive, vol. 7, pp. 99112, 2008.
[3] J. N. Luftman, R. Kempaiah, and E. Nash, "Key Issues for IT Executives 2005," MISQ Executive, vol. 5, pp. 81-99, 2006.

[4] J. N. Luftman, R. Kempaiah, and E. H. Rigoni, "Key Issues for IT Executives 2008," MISQ Executive, vol. 8, pp. 151-159, 2009.

[5] J. C. Henderson and N. Venkatraman, "Strategic Alignment: Leveraging Information Technology for Transforming Organizations," IBM Systems Journal, vol. 38, pp. 472-484, 1999.

[6] J. N. Luftman, "Assessing Business-IT Alignment Maturity," Communications of the Association for Information Systems (AIS), vol. 4, pp. 1-50, 2000.

[7] D. Sledgianowski and J. N. Luftman, "IT-Business Strategic Alignment Maturity: A Case Study," Journal of Cases on Information Technology, vol. 7, pp. 102-120, 2005.

[8] U. Baumöl, "Methodenkonstruktion für das Business-ITAlignment," Wirtschaftsinformatik, vol. 48, pp. 314 322, 2006.

[9] D. F. Tyler and T. P. Cathcart, "A structured Method for Developing Agile Enterprise Architectures," in International Conference on Agile Manufacturing (ICAM 2006), Norfolk, Virginia, USA, 2006, pp. 1-8.

[10] M. Rohloff, "Framework and Reference for Architecture Design," in 14th Americas Conference on Information Systems (AMCIS 2008), Toronto, 2008.

[11] IEEE, "IEEE Recommended Practice for Architectural Description of Software Intensive Systems (IEEE Std 1471-2000)," IEEE Computer Society, New York, NY 2000.

[12] H. Jonkers, M. M. Lankhorst, H. W. L. Doest, F. Arbab, H. Bosma, and R. J. Wieringa, "Enterprise architecture: Management tool and blueprint for the organisation," Information Systems Frontiers, vol. 8, pp. 63-66, 2006.

[13] M. Lankhorst, Enterprise Architecture at Work: Modelling, Communication and Analysis. Berlin et al.: Springer, 2005.

[14] R. Winter and R. Fischer, "Essential Layers, Artifacts, and Dependencies of Enterprise Architecture," Journal of Enterprise Architecture, vol. 3, pp. 7-18, 2007.

[15] The Open Group, "TOGAF (The Open Group Architecture Framework) Version 9," 2009.

[16] M. Lankhorst, E. Proper, and H. Jonkers, "The Architecture of the ArchiMate Language," in 10th International Workshop, BPMDS 2009, and 14th International Conference, EMMSAD 2009, held at CAiSE 2009, Amsterdam, 2009.

[17] Ministry of Defence, "MOD Architecture Framework version 1.2.003," Ministry of Defence, UK 2008.

[18] Department of Defense Architecture Framework Working Group, "DoD Architecture Framework, version 1.5," Department of Defense, USA 2007. 
[19] P. Johnson and M. Ekstedt, Enterprise Architecture: Models and Analyses for Information Systems Decision Making. Pozkal: Studentlitteratur, 2007.

[20] S. Aier and R. Winter, "Virtual Decoupling for IT/Business Alignment - Conceptual Foundations, Architecture Design and Implementation Example," Business \& Information Systems Engineering, vol. 51, pp. 150-163, 2009.

[21] L. Plazaola, J. Flores, E. Silva, N. Vargas, and M. Ekstedt, "An Approach to Associate Strategic Business-IT alignment Assessment to Enterprise Architecture," in Fifth Conference on Systems Engineering 2007 (CSER2007), New Jersey, 2007.

[22] J. A. Zachman, "A Framework for Information Systems Architecture," IBM Systems Journal, vol. 26, pp. 276-292, 1987.

[23] ISO/IEC, "Software engineering - Product quality Part 3: Internal metrics," International Organization for Standardization, International standard ISO/IEC TR 9126-3:2003(E), July 2003.

[24] ISO/IEC, "Software engineering - Product quality Part 1: Quality model," International Organization for Standardization, International standard ISO/IEC TR 9126-1:2001(E), June 2001.

[25] ISO/IEC, "Software engineering - Product quality Part 2: External metrics," International Organization for Standardization, International standard ISO/IEC TR 9126-2:2003(E), July 2003.

[26] ISO/IEC, "ISO/IEC 42010:2007 - Systems and software engineering - Recommended practice for architectural description of software-intensive systems," ISO 2007.

[27] C. U. Smith and L. G. Williams, Performance Solutions: A Practical Guide to Creating Responsive, Scalable Software: Addison Wesley, 2001.

[28] IEEE, "IEEE Standard Glossary of Software Engineering Technology," The Institute of Electrical and Electronics Engineers 1990.

[29] G. Dhillon and J. Backhouse, "Information System Security Management in the New Millennium," Communications of the ACM, vol. 43, 2000.

[30] D. Ferraiolo and R. Kuhn, "Role-Based Access Control," in 15th National Computer Security Conference, 1992, pp. 554-563.

[31] M. Matinlassi and E. Niemelä, "The Impact of Maintainability on Component-based Software Systems," in 29th IEEE EUROMICRO Conference "New Waves in System Architecture", 2003.

[32] M. Gammelgård, M. Ekstedt, and P. Gustafsson, "A Categorization of Benefits From IS/IT Investments," in 13th European Conference on Information Technology Evaluation (ECITE 2006), Genoa, 2006.
[33] P. Gustafsson, U. Franke, D. Höök, and P. Johnson, "Quantifying IT impacts on organizational structure and business value with Extended Influence Diagrams," in First IFIP WG 8.1 Working Conference: The Practice of Enterprise Modeling (PoEM 2008), Stockholm, 2008, pp. 138-152.

[34] ITGI, IT Governance Institute: Cobit 4.1. Rolling Meadows: IT Governance Institute, 2007.

[35] B. J. Thompson, Exploratory and Confirmatory Factor Analysis: Understanding Concepts and Applications. Washington, DC: American Psychological Association, 2004.

[36] T. A. Brown, Confirmatory Factor Analysis for Applied Research, 18 ed. New York, London: Guilford, 2006.

[37] A. D. Gordon, "Hierarchical Classification," in Clustering and Classification, P. Arabie, L. J. Hubert, and G. De Soete, Eds. River Edge, NJ: World Scientific Publishing, 1996, pp. 65-121.

[38] W. Härdle and L. Simar, Applied Multivariate Statistical Analysis. Berlin: Springer, 2003.

[39] H. F. Kaiser and J. Rice, "Little Jiffy, Mark Iv," Educational and Psychological Measurement, vol. 34, pp. 111-117, 1974.

[40] H. F. Kaiser and K. W. Dickman, "Analytic Determination of Common Factors," American Psychological Reports, vol. 14, pp. 425-430, 1959.

[41] R. B. Cattell, "The Scree Test for the Number of Factors," Multivariate Behavioral Research, vol. 1, pp. 245-276, 1966.

[42] H. F. Kaiser, "The Varimax Criterion for Analytic Rotation in Factor Analysis," Psychometrika, vol. 23, pp. 187-200, 1958.

[43] J. F. Hair Jr, B. Black, and B. Babin, Multivariate Data Analysis, 6 ed. New Jersey: Prentice Hall, 2006. 